\title{
Characterization of low-cost Brazilian resin composites submitted to tooth brushing
}

\section{Marcela Alvarez FERRETTI (a) \\ Renata PEREIRA(a) \\ Rodrigo Barros Esteves LINS(a) \\ Mariana Gusmão Corsini SOARES(a) \\ Larissa Jacó Hessel PINTO(a) \\ Luís Roberto Marcondes MARTINS(a) \\ Flávio Henrique Baggio AGUIAR (a)}

(a) Universidade Estadual de Campinas - Unicamp, Piracicaba Dental School, Department of Restorative Dentistry, Piracicaba, SP, Brazil.

Declaration of Interests: The authors certify that they have no commercial or associative interest that represents a conflict of interest in connection with the manuscript.

\section{Corresponding Author:}

Marcela Alvarez Ferretti

E-mail: marcela.a.ferretti@gmail.com

Submitted: January 30, 2020

Accepted for publication: July 29, 2020

Last revision: August 21, 2020

\begin{abstract}
This in vitro study aimed to evaluate surface microhardness, roughness, color, gloss and topography of low-cost Brazilian resin composites, compared with an international one. All 120 samples $(8 \mathrm{~mm}$ $\varnothing \times 2 \mathrm{~mm}$ height) were prepared and divided into 5 groups: Ultrafill (Biodinâmica), Llis (FGM), Fill Magic (Coltene), Applic (Makira), and Filtek Z250XT (3M Oral Care). Surface microhardness (KHN) (n=10) was analyzed at two time periods: before and after simulated tooth brushing (STB). Other standardized samples of each group $(n=10)$ were analyzed for surface roughness $(\mathrm{Ra})$, color $\left(\Delta \mathrm{L}, \Delta \mathrm{a}, \Delta \mathrm{b}, \Delta \mathrm{E}, \Delta \mathrm{E}_{00}\right)$ and gloss unit (GU) at the same two periods. The topography of non-brushed and brushed samples of each group $(n=4)$ was evaluated by scanning electron microscopy. Data were analyzed statistically by two-way repeated measures ANOVA with Bonferroni post-hoc test (KHN, Ra, $\mathrm{GU})$, and one-way ANOVA with Tukey post-hoc test $\left(\Delta \mathrm{L}, \Delta \mathrm{a}, \Delta \mathrm{b}, \Delta \mathrm{E}, \Delta \mathrm{E}_{00}\right)$ $(\alpha=0.05)$. Topographic images were submitted to descriptive analysis. The low-cost Brazilian resin composites investigated were compared with the international one and revealed: lower $\mathrm{KHN}$, regardless of before or after STB; statistically similar Ra before STB, except Ultrafill, which presented higher values; lower Ra after STB, except Ultrafill, which presented statistically similar values; statistically similar color change in $\Delta \mathrm{L}, \Delta \mathrm{a}, \Delta \mathrm{b}$ parameters; statistically similar color change in $\Delta \mathrm{E}, \Delta \mathrm{E} 00$ parameters, except Fill Magic, which presented lower values; lower gloss before STB; lower gloss after STB, except Ultrafill, which presented statistically similar values. In a situation of scarce resources, low-cost Brazilian composites might be an acceptable cost-effective restorative alternative.
\end{abstract}

Keywords: Composite Resins; Surface Properties; Toothbrushing.

\section{Introduction}

The search for quality of life and healthcare has intensified in recent years. Moreover, since it has become increasingly easier to find information, and dentistry has become globalized, people of all ages have become more demanding about restorative dentistry treatments. ${ }^{1,2}$ As a result, there has been a remarkable increase in the demand for dental services in Brazil. ${ }^{3,4}$ Among the options available today, there are not only public and private dental clinics, but countless health insurance providers and 
exclusively dental insurance plans that facilitate the access to treatment of people from different socioeconomic groups. The services are affordable, and payment options range. ${ }^{3}$ According to data from the National Supplementary Health Agency, the number of health plan beneficiaries increased 25\% from 2008 to $2013 .{ }^{5}$ Exclusively dental health insurance grew from 2.7 million in December 2000 to 16 million in September 2011.

On one hand, it is desirable for the population to have easy access to dental treatment; on the other hand, it is important to consider the resources used in clinical procedures, and the implications of low-cost treatments on dental profits. According to Hebling et al., ${ }^{6}$ although fixed quotations may range among dental clinics, some variable costs are established by criteria that do not depend only on the operator, such as the cost of dental materials. In the case of resin composites, for instance, the price is set by the material suppliers, the amount to be used is determined by the cavity size, and the choice of material should be based on scientific evidence. ${ }^{7,8}$ Thus, one may speculate that the cost quotations given by popular dental clinics for composite dental work does not have to be high in order for these clinics to profit from standard restorative treatments. However, cost savings may imply loss of effectiveness.

Effectiveness should be an acceptable and not the highest amount, so that the intervention may be cost-effective. ${ }^{9}$ Nevertheless, whether the price of the composites is directly proportional to the quality of the treatment remains unknown. Costeffectiveness studies in the area of restorative dentistry are scarce, and, when available, normally consider restoration survival, ${ }^{10,11}$ and not exactly the properties of the materials.

Considering that the clinical success of restorative procedures largely depends on the quality of the material used, and that resin composites are used for multiple purposes in dentistry, ${ }^{2,12}$ it is essential that professionals select efficient and quality materials, based on their scientifically evaluated properties. To date, there are no reports in the literature on the properties of low-cost Brazilian resin composites. Thus, this in vitro study aimed to evaluate the surface microhardness, roughness, color, gloss and topography of four low-cost Brazilian composites, before and after simulated tooth brushing, compared to a standard international one. All the Brazilian resin composites (Ultrafill, Llis, Fill Magic and Applic) evaluated in this study were low-cost products available on the local market, and all widely used in dental clinics in Brazil. They were compared with an international resin composite, considered of satisfactory quality (Filtek Z250 $X T)$. The alternative hypotheses tested were: a) the international resin composite would present surface properties superior to the Brazilian composites; $b$ ) simulated tooth brushing would negatively influence the tested properties of both the Brazilian and the international products.

\section{Methodology}

\section{Sample preparation}

A total of 120 samples were prepared from five different micro- and nanohybrid resin composites, and divided into five groups: Ultrafill (Biodinâmica, Ibiporã, Brazil); Llis (FGM, Joinville, Brazil); Fill Magic (Coltene, Rio de Janeiro, Brazil); Applic (Makira, Maringá, Brazil); Filtek Z250 XT (3M Oral Care, St. Paul, , USA). The composition and prices of all the resin composites are presented in Table 1 . The price of each composite, in local currency (reais: $\mathrm{R} \$$ ), was converted to American dollars according to the exchange rate of May 2020 (US\$1.00 = R \$ 5.34).

All the samples were prepared using a silicon matrix with an orifice of $8 \mathrm{~mm} \varnothing \times 2 \mathrm{~mm}$ height. The independent variables tested were as follows: surface microhardness $(\mathrm{n}=10)$; surface roughness, color and gloss $(n=10)$; and surface topography $(n=4)$. The matrix orifice was filled with a single resin composite increment. Afterwards, a polyester strip covered by a glass coverslip was positioned over the material. The glass coverslip was pressed with a $500 \mathrm{~g}$ load for $3 \mathrm{~min}$ to ensure better compaction of the resin composite to prevent voids in the sample body. The composites were light-cured (Valo, Ultradent Products, S. Jordan, USA) at $1,400 \mathrm{~mW} / \mathrm{cm}^{2}$, and measured by a power meter (Ophir Optronics, Jerusalem, Israel) for 20 or $40 \mathrm{~s}$, according to the manufacturer's instructions. 
Table 1. Materials specifications as reported by the manufacturer.

\begin{tabular}{|c|c|c|c|c|c|c|c|c|}
\hline Resin composite & Classification & $\begin{array}{l}\text { Lot } \\
\text { number }\end{array}$ & Manufacturer & Matrix composition & $\begin{array}{c}\text { Filler loading } \\
\text { (volume \%) }\end{array}$ & Shade & $\begin{array}{l}\text { Curing } \\
\text { time }\end{array}$ & $\begin{array}{l}\text { Price } \\
\text { (R\$/U\$) }\end{array}$ \\
\hline Ultrafill & Microhybrid & 36218 & $\begin{array}{l}\text { Biodinâmica, } \\
\text { Ibiporã, Brazil }\end{array}$ & $\begin{array}{l}\text { BisGMA, UEDGMA, Inorganic } \\
\text { Filler, Pigments, Catalysts }\end{array}$ & 79 & $\mathrm{~A} 2$ & $40 s$ & $\begin{array}{l}\mathrm{R} \$ 13.99 / \\
\mathrm{U} \$ 2.61^{*}\end{array}$ \\
\hline Llis & Nanohybrid & 230718 & $\begin{array}{c}\text { FGM, Joinville, } \\
\text { Brazil }\end{array}$ & $\begin{array}{c}\text { BisGMA, TEGDMA, Bis-EMA, } \\
\text { Camphorquinone, Co- } \\
\text { initiators, Silane, Barium- } \\
\text { Aluminum Silicate Glass, } \\
\text { Silicon Dioxide Nanoparticles. }\end{array}$ & $56-59$ & EA2 & $20 \mathrm{~s}$ & $\begin{array}{l}\mathrm{R} \$ 22.61 / \\
\mathrm{U} \$ 4.23^{*}\end{array}$ \\
\hline Fill magic & Microhybrid & 1702599 & $\begin{array}{c}\text { Coltene, Rio } \\
\text { de Janeiro, } \\
\text { Brazil }\end{array}$ & $\begin{array}{l}\text { Bis-GMA, Bis-EMA, UDMA, } \\
\text { TEGDMA, photoinitiator, } \\
\text { fillers, pigments. }\end{array}$ & 75 & A2 & $40 \mathrm{~s}$ & $\begin{array}{l}\mathrm{R} \$ 17.49 / \\
\mathrm{U} \$ 3.27^{*}\end{array}$ \\
\hline Applic & Nanohybrid & 45918 & $\begin{array}{c}\text { Maquira, } \\
\text { Maringá, Brazil }\end{array}$ & $\begin{array}{l}\text { Bis-GMA, UDMA, TEGDMA, } \\
\text { Camphorquinone, Chivacure } \\
\text { EPD, Butyl Hydroxy Toluene, } \\
\text { Aerosil OX 50, Aluminum, } \\
\text { Boron Silicate, Yellow Iron } \\
\text { Oxide, Red Iron Oxide, Black } \\
\text { Iron Oxide }\end{array}$ & $56-59$ & EA2 & $20 \mathrm{~s}$ & $\begin{array}{l}\mathrm{R} \$ 24.90 / \\
\mathrm{U} \$ 4.66^{*}\end{array}$ \\
\hline Filtek Z250 XT & Microhybrid & 933261 & $\begin{array}{c}\text { 3M Oral Care, } \\
\text { St. Paul, USA }\end{array}$ & $\begin{array}{c}\text { Bis-EMA, Bis-GMA, UDMA, } \\
\text { TEGDMA, PEGDMA, Treated } \\
\text { Silanized Ceramics, Silane } \\
\text { Treated Silica. }\end{array}$ & 67.8 & $\mathrm{~A} 2$ & $20 \mathrm{~s}$ & $\begin{array}{c}\mathrm{R} \$ 77.0 / \\
\text { U\$14.41* }\end{array}$ \\
\hline
\end{tabular}

Bisphenol A Diglycidyl Ether Dimethacrylate (Bis-GMA); Triethylene Glycol Dimethacrylate (TEGDMA); Ethoxylated Bisphenol A Glycol Dimethacrylate (Bis-EMA); Diurethane Dimethacrylate (UDMA); Ethylene Urethane Dimethacrylate (UEDGMA), Polyethylene Glycol Dimethacrylate (PEGDMA). *Reference values of May 28, 2020

The light-curing unit was positioned directly over the polyester strip. The tip diameter was measured with a digital caliper (Mitutoyo Corporation, Tokyo, Japan), and the tip area was determined in $\mathrm{cm}^{2}$. Irradiance $\left(\mathrm{mW} / \mathrm{cm}^{2}\right)$ was calculated by dividing the optical power by the tip area.

Samples were dried-stored at $37^{\circ} \mathrm{C}$. After $24 \mathrm{~h}$, they were submitted to finishing and polishing in a polishing machine (APL-4, Arotec, São Paulo, Brazil) with \#1,200, \#2,000, and \#4,000 grit carbide sandpaper (Carbimet Paper Discs, Buehler, Lake Bluff, USA), under water-cooling. The samples were cleaned in ultrasonic baths (1440 D-, Odontobrás, Rio Preto, Brazil) for 15 minutes between sanding with each grit.

\section{Simulated tooth brushing}

Simulated tooth brushing was performed using one soft toothbrush (Oral B Indicator Plus - Procter \& Gamble, Cincinnati, USA) for each sample. First, the toothbrush handle and head were separated by sectioning with a double-sided diamond disk (KG Sorensen, Barueri, Brazil). Afterwards, the brush head was fixed to the brush holder device of a simulated brushing machine (MSet, Marcelo Nucci ME, São Carlos, SP, Brazil) with thermoplastic glue (Brascola, São Bernardo do Campo, Brazil), so that the toothbrush bristles remained in contact with the surface of the sample throughout all brushing cycles. The simulated tooth brushing process was performed according to ISO/TS 14569-2 specifications. ${ }^{13}$

A slurry solution was used to brush the samples. It consisted of toothpaste (Colgate Maximal Caries Protection, Colgate Palmolive Company, São Paulo, Brazil) diluted in distilled water, at a concentration of $3 \mathrm{~g} / \mathrm{ml}$ (3:1), in accordance with ISO 11609:2010 standards. ${ }^{14}$ Each sample was submitted to linear brushing movements, totaling 20,000 movements (10,000 cycles), which correspond to approximately 12 months of brushing, at a frequency of $5 \mathrm{~Hz}$, and under a $200 \mathrm{~g}$ load, to simulate the force applied during oral hygiene procedures. ${ }^{15,16,17}$ At the end of the brushing cycles, the samples were removed from the machine, washed with distilled water, dried with absorbent paper (Kleenex, Kimberly-Clark, São Paulo, SP, Brazil) and submitted to surface microhardness, roughness, color, gloss and topography analyses. 


\section{Knoop Microhardness Analysis (KHN)}

Microhardness analysis was performed with a microhardness tester (HMV-2000, Shimadzu Corporation, Tokyo, Japan). A Knoop diamond indenter applied a static load of $50 \mathrm{gf}$ for $15 \mathrm{~s}$ to the top surfaces of the samples. Three Knoop indentations were made on the upper surface of each sample: one at the center and two at a distance of $200 \mu \mathrm{m}$ from the center. The average value of the indentation measurements was used in the statistical analysis as the KHN value for each sample. The measurements were repeated after simulated tooth brushing. ${ }^{18}$

\section{Surface roughness analysis $(\mathbf{R a})$}

Surface roughness was measured using a profilometer (Surftest 211, Mitutoyo, Tokyo, Japan). Each sample was positioned perpendicular to the profile tip, and the Ra values (arithmetic mean of surface roughness) were obtained using a cut-off of $0.25 \mathrm{~mm}$, with $0.05 \mathrm{~mm} / \mathrm{s}$ speed. Three equidistant measurements were performed per sample. The mean of the measurements was calculated and tabulated. These measurements were repeated after simulated tooth brushing. ${ }^{19}$

\section{Color analysis}

Color was measured using a spectrophotometer (CM700D, Minolta, Osaka, Japan) previously calibrated according to the manufacturer's specifications. Samples were placed in a polytetrafluoroethylene-based device, in ambient light condition (GTI MiniMatcher MM-1, GTI Technology, Newburgh, USA). ${ }^{19}$ The mean values of three readings were calculated for each sample. These values were quantified in the CIE $L^{*}, a^{*}, b^{*}$ color system, used in color software (Konica Minolta, Chiyoda, Tokyo, Japan), in three coordinates, to allow the calculation of color change $(\Delta \mathrm{E})=\left[(\mathrm{L} 1-\mathrm{L} 0)^{2}+\right.$ $\left.(\mathrm{a} 1-\mathrm{a} 0)^{2}+(\mathrm{b} 1-\mathrm{b} 0)^{2}\right]^{1 / 2}$ and CIEDE2000 color difference $\left(\Delta \mathrm{E}_{00}\right)=\left[\left(\Delta \mathrm{L}^{\prime} / \mathrm{K}_{\mathrm{L}} \mathrm{S}_{\mathrm{L}}\right)^{2}+\left(\Delta \mathrm{C}^{\prime} / \mathrm{K}_{\mathrm{C}} \mathrm{S}_{\mathrm{C}}\right)^{2}+\left(\Delta \mathrm{H}^{\prime} / \mathrm{K}_{\mathrm{H}} \mathrm{S}_{\mathrm{H}}\right)^{2}+\right.$ $\left.\mathrm{R}_{\mathrm{T}}{ }^{*}\left(\Delta \mathrm{C}^{\prime} / \mathrm{K}_{\mathrm{C}} \mathrm{S}_{\mathrm{C}}\right) *\left(\Delta \mathrm{H}^{\prime} / \mathrm{K}_{\mathrm{H}} \mathrm{S}_{\mathrm{H}}\right)\right]^{1 / 2}$ (Paravina 2015, Perez 2016) ${ }^{20,21}$ The readings were also taken after simulated tooth brushing. The International Commission on Illumination - CIE L* $a^{*} b^{*}$ represents color parameters in three dimensions, indicating variations of lightness for $\mathrm{L}^{*}$ parameter (black-white), and chrome for $\mathrm{a}^{*}$ (red-green) and $b^{*}$ (yellow-blue) parameters. ${ }^{21}$

\section{Gloss analysis (GU)}

The gloss of the samples was measured by ZGM Glossmeter (Zehntner Testing Instruments, Sissach, Switzerland), in gloss units (GU). The device projects a beam of light at angles of $20^{\circ}, 60^{\circ}$ or $85^{\circ}$. The angle of $60^{\circ}$ was applied to evaluate the gloss at the center of the sample, and also perform the entire assessment (ISO - Standards, ISO 2813:2014). ${ }^{22}$ A metallic sample holder with the same dimensions as the sample was used to avoid the influence of external illumination. Three measurements were performed per sample. The mean of each three values of gloss unit was calculated and tabulated. These measurements were repeated after the simulated tooth brushing procedure. ${ }^{19}$

\section{Surface topography analysis by Scanning Electron Microscopy (SEM)}

Four samples of each group were prepared to analyze surface topography by SEM. Characterization of the topography was determined by comparing the time periods before and after brushing, using two samples of each group analyzed before simulated tooth brushing with two others after simulated tooth brushing. The samples were coated with palladiumgold alloy under high vacuum (SCD 050, BALTECAG, Balzers, Liechtenstein) and analyzed by SEM (JSM 5600 LV, JEOL, Tokyo, Japan). Image magnifications of 5000x were obtained.

\section{Statistical analyses}

Statistical analyses were performed with SPSS 21.0 (SPSS, Chicago, USA). Shapiro-Wilk, Kolmogorov-Smirnov and Levene tests were conducted to confirm data normality and equality of variances. Microhardness (KHN), roughness (Ra) and gloss unit (GU) were analyzed by twoway repeated measures ANOVA with Bonferroni post-hoc test. CIELab parameters $\left(\Delta \mathrm{L}^{*}, \Delta \mathrm{a}^{*}, \Delta \mathrm{b}^{*}\right)$, color change $(\Delta \mathrm{E})$ and CIEDE2000 color difference $\left(\Delta \mathrm{E}_{00}\right)$ were analyzed by one-way ANOVA with Tukey post-hoc test, with the significance level set at $5 \%$. Topographic images were submitted to descriptive analysis. 


\section{Results}

\section{Knoop microhardness (KHN)}

The Knoop microhardness values before and after simulated tooth brushing are shown in Table 2. Before brushing, Filtek Z250XT presented higher KHN values than the Brazilian composites ( $\mathrm{p}<0.001$ ). Fill Magic exhibited lower KHN values than the other Brazilian composites ( $p$ < 0.015). After brushing, Filtek Z250 XT also presented higher KHN values than the Brazilian composites $(\mathrm{p}<0.004)$, and all the Brazilian composites presented similar results $(\mathrm{p}>0.05)$. The microhardness values of all the composites significantly increased after brushing $(\mathrm{p}<0.036)$.

\section{Surface roughness $(\mathbf{R a})$}

The surface roughness values are shown in Table 3. Before simulated tooth brushing, Ultrafill

Table 2. Mean and standard deviation (SD) of Knoop Microhardness $(\mathrm{KNH})$ before and after simulated tooth brushing.

\begin{tabular}{|c|c|c|}
\hline \multirow{2}{*}{ Resin composite } & \multicolumn{2}{|c|}{ Simulated tooth brushing } \\
\hline & Before & After \\
\hline Ultrafill & $65.06(5.47) \mathrm{Bc}$ & $79.34(12.41) \mathrm{Ab}$ \\
\hline Llis & 68.57 (5.73) Bbc & $77.94(9.73) \mathrm{Ab}$ \\
\hline Fill Magic & $59.35(4.01) \mathrm{Bd}$ & 73.01 (9.28) Ab \\
\hline Applic & $71.71(5.38) \mathrm{Bb}$ & $81.60(7.18) \mathrm{Ab}$ \\
\hline Filtek Z250 XT & $85.55(6.36) \mathrm{Ba}$ & $94.56(2.36) \mathrm{Aa}$ \\
\hline
\end{tabular}

Mean values followed by the same letters did not differ statistically $(p>0.05)$. Uppercase letters compare different time periods for the same resin composite (rows), whereas lowercase letters compare different resin composites at the same time period (columns).

Table 3. Mean and standard deviation (SD) of roughness (Ra).

\begin{tabular}{lcc}
\hline \multirow{2}{*}{ Resin composite } & \multicolumn{2}{c}{ Simulated tooth brushing } \\
\cline { 2 - 3 } Ultrafill & \multicolumn{1}{c}{ Before } & After \\
Llis & $0.156(0.01) \mathrm{Ba}$ & $0.197(0.04) \mathrm{Aab}$ \\
Fill Magic & $0.117(0.02) \mathrm{Bb}$ & $0.145(0.04) \mathrm{Ac}$ \\
Applic & $0.133(0.02) \mathrm{Bb}$ & $0.156(0.03) \mathrm{Ac}$ \\
Filtek Z250 XT & $0.137(0.01) \mathrm{Bb}$ & $0.187(0.03) \mathrm{Ab}$ \\
\hline
\end{tabular}

Mean values followed by the same letters did not differ statistically $(p>0.05)$. Uppercase letters compare different time periods for the same resin composite (rows), whereas lowercase letters compare different resin composites at the same time period (columns). presented the highest values of all resin composites $(\mathrm{p}<0.048)$. Llis, Fill Magic, Applic and Filtek Z250 $X T$ showed no differences in Ra values among themselves ( $p>0.05)$. After brushing, Filtek Z250 $\mathrm{XT}$ and Ultrafill showed higher roughness values than Llis and Fill Magic. Fill Magic was similar to Llis ( $p>0.05)$. The surface roughness of all the composites increased after brushing.

\section{Color}

Table 4 shows the values of color change after simulated tooth brushing. $\Delta \mathrm{L}$ and $\Delta \mathrm{b}$ coordinates did not present any differences among the resin composites $(\mathrm{p}>0.05)$. The $\Delta$ a coordinate presented higher values for Applic, Filtek Z250 XT, and Ultrafill $(p>0.05)$. However, Filtek Z250 XT did not differ from the other resin composites, and Llis showed lower values compared with Ultrafill and Applic $(\mathrm{p}<0.018)$. $\Delta \mathrm{E}$ and $\Delta \mathrm{E}_{00}$ showed statistical differences between Filtek Z250 XT and Fill Magic ( $<$ 0.041). The other groups did not show any statistical differences among one another $(\mathrm{p}>0.05)$.

\section{Gloss (GU)}

Table 5 shows the gloss values. Before simulated tooth brushing, Filtek Z250 XT obtained higher values than the Brazilian composites ( $p<0.046)$. Ultrafill presented lower gloss values than Filtek Z250 XT, Fill Magic and Applic, but values similar to Llis ( $p>0.05)$. Llis, Fill Magic and Applic did not differ among one another $(p>0.05)$. After brushing, Filtek Z250 XT presented higher gloss values than the Brazilian composites ( $p<0.018)$, except for Ultrafill ( $p=0.064)$. The other composites did not differ statistically from one another $(p>0.05)$. After brushing, all the composites showed a decrease in gloss values $(p<0.001)$.

\section{Surface topography by SEM}

Figure represents the surface topography of the composites obtained by SEM. Although Ultrafill, Llis, Fill Magic and Applic presented some slight deformations before brushing, overall, all the groups had homogeneous surfaces in comparison with the same groups after brushing. In the case of Applic, exposure of filler particles is noticeable. After brushing, 
Table 4. Mean and standard deviation (SD) of difference of CIELab parameters ( $\Delta \mathrm{L}, \Delta \mathrm{a}$ and $\Delta \mathrm{b})$, color change $(\Delta \mathrm{E})$ and $\mathrm{ClEDE} 2000$ color difference $\left(\Delta \mathrm{E}_{00}\right)$, after simulated tooth brushing protocol.

\begin{tabular}{lccccc}
\hline Resin composite & $\Delta \mathrm{L}$ & $\Delta \mathrm{a}$ & $\Delta \mathrm{b}$ & $\Delta \mathrm{E}$ & $\Delta \mathrm{E}_{00}$ \\
\hline Ultrafill & $-0.73(0.83) \mathrm{a}$ & $0.44(0.13) \mathrm{ab}$ & $-1.17(0.49) \mathrm{a}$ & $1.95(0.58) \mathrm{ab}$ & $1.17(0.52) \mathrm{ab}$ \\
Llis & $-0.57(0.77) \mathrm{a}$ & $-0.03(0.62) \mathrm{c}$ & $-1.07(0.89) \mathrm{a}$ & $1.62(0.69) \mathrm{ab}$ & $0.98(0.58) \mathrm{ab}$ \\
Fill Magic & $-0.33(0.77) \mathrm{a}$ & $0.12(0.11) \mathrm{bc}$ & $-1.04(0.17) \mathrm{a}$ & $1.30(0.24) \mathrm{b}$ & $0.88(0.18) \mathrm{b}$ \\
Applic & $-0.87(0.73) \mathrm{a}$ & $0.58(0.18) \mathrm{a}$ & $-1.35(0.21) \mathrm{a}$ & $1.83(0.31) \mathrm{ab}$ & $1.37(0.29) \mathrm{ab}$ \\
Filtek Z50XT & $-0.49(0.52) \mathrm{a}$ & $0.35(0.27) \mathrm{abc}$ & $-1.25(2.59) \mathrm{a}$ & $2.48(1.50) \mathrm{a}$ & $1.61(0.76) \mathrm{a}$ \\
\hline
\end{tabular}

Mean values followed by the same letters did not differ statistically $(p>0.05)$. Lowercase letters compare different resin composites for the same variable (rows).

Table 5. Mean and standard deviation (SD) of gloss.

\begin{tabular}{lcc}
\hline \multirow{2}{*}{ Resin composite } & \multicolumn{2}{c}{ Simulated tooth brushing } \\
\cline { 2 - 3 } & \multicolumn{1}{c}{ Before } & After \\
\hline Ultrafill & $77.93(3.60) \mathrm{Ac}$ & $18.14(9.87) \mathrm{Bab}$ \\
Llis & $81.49(8.20) \mathrm{Abc}$ & $16.36(4.66) \mathrm{Bb}$ \\
Fill Magic & $83.42(5.98) \mathrm{Ab}$ & $18.74(4.09) \mathrm{Bb}$ \\
Applic & $85.86(2.77) \mathrm{Ab}$ & $18.13(5.78) \mathrm{Bb}$ \\
Filtek Z50 XT & $88.78(3.25) \mathrm{Aa}$ & $27.31(6.83) \mathrm{Ba}$ \\
\hline
\end{tabular}

Mean values followed by the same letters did not differ statistically $(p>0.05)$. Uppercase letters compare different time periods for the same resin composite (rows), whereas lowercase letters compare different resin composites at the same time period (columns).

the homogeneity of exposed filler particle sizes could be observed for Ultrafill, Llis, Fill Magic and Applic. Even so, the spatial conformity of each filler particle is irregular. Contrarily, the size of the Filtek Z250XT filler particles is heterogeneous (some particles are smaller than others), whereas their spatial conformity is more rounded and regular.

\section{Discussion}

Although the physicomechanical properties and characterization of costly resin composites made by international manufacturers are well elucidated in the literature, to the best of our knowledge, no previous study has explored the surface characteristics of low-cost Brazilian resin composites. This study reports the surface microhardness, roughness, color, gloss and topography of four low-cost Brazilian resin composites, compared to a standard international one, before and after simulated tooth brushing, bearing in mind that all are widely used in dental clinics in Brazil.

The first hypothesis was that the international resin composite would present properties superior to those of the Brazilian composites, and was rejected. Although Filtek Z250 XT presented the highest microhardness and gloss values, both before and after simulated tooth brushing, the surface roughness evaluation showed that Filtek Z250 XT presented higher values than Fill Magic, Llis and Applic after brushing. In addition, the color of Filtek Z250 XT underwent greater change than that of Fill Magic. Such varied results after brushing led to the rejection of the second hypothesis (simulated tooth brushing would negatively influence the tested properties).

Filtek Z250 XT contains nano-zirconia/silica spheroidal particles and a relatively soft organic matrix of Bis-GMA, UDMA and TEGDMA. ${ }^{23}$ The hardness of the zirconia particles may have caused the brushing cycles to wear them out to a lesser extent than the soft organic matrix, resulting in an irregular surface. Evidence of this is given in Figure 1, which shows that the interparticle spacing of Filtek Z250 XT after brushing seems to be greater than that of the other composites. The same results of this morphological analysis were found in previous studies. ${ }^{24}$ As stated by Ruivo et al., ${ }^{25}$ the greater the interparticle spacing, the less protected the soft resin matrix against challenges, such as brushing. A point to be borne in mind herein is that roughness values above $0.2 \mu \mathrm{m}$ allow greater biofilm retention, representing a disadvantage to any material that may be used. ${ }^{26}$ In this study, Filtek Z250 XT was the only resin composite that presented an average 

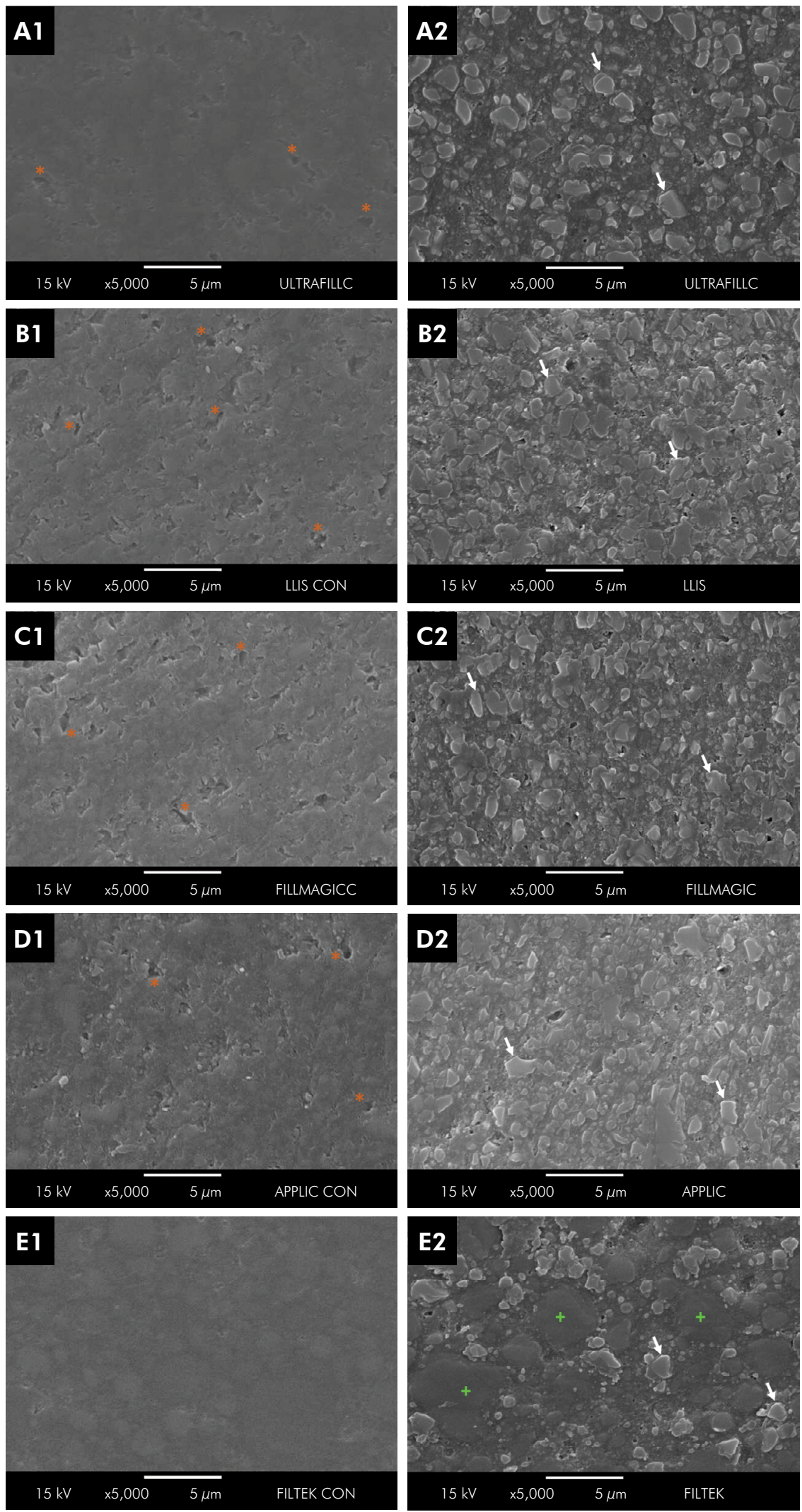

Legend: A) Ultrafill; B) Llis; C) Fill Magic; D) Applic; E) Filtek Z250 XT. / White arrows indicate inorganic fillers from each composite; green plus symbols $(+)$ indicate small inorganic Filtek Z250 XT fillers; orange asterisks $\left(^{*}\right)$ indicate orifices of Brazilian resin composite before simulated tooth brushing.

Figure. SEM images (5,000x magnification) showing the surface before (1) and after (2) simulated tooth brushing of each composite group. 
roughness above $0.2 \mu \mathrm{m}$ after brushing, a value statistically similar to that of Ultrafill.

Filtek Z250 XT and Ultrafill presented higher roughness after brushing, owing to differences in hardness between their organic matrix and filler particles. Nevertheless, it should be pointed out that the same increase in the roughness pattern was observed for all the composites after brushing. The present results are in accordance with previous studies, which also tested composites after brushing cycles. ${ }^{25,27,28,29}$ As elucidated by Puckett et al. ${ }^{30}$ when composites are submitted to brushing, chewing and other strains, the distance between valleys and peaks is increased, resulting in higher surface roughness. In sum, the organic matrix is worn during brushing, leading to protrusion or even removal of fillers, and consequent development of bumps and pits. ${ }^{25}$ Indeed, the increase in microhardness and the decrease in gloss of all composites after brushing suggest overall filler exposure. These findings are in agreement with previous studies, which indicate inverse correlation between roughness and gloss. ${ }^{23,31}$

It is worth noting that roughness depends on the duration of the brushing ${ }^{17,29,32,33}$ and the load applied by the patient on the length of the toothbrush bristles, ${ }^{34,35}$ combined with the abrasives contained in the toothpastes. ${ }^{36}$ In addition, the composite characteristics, i.e. organic and inorganic matrix, particle size, spatial conformation, hardness and distribution, may play a role in the wear pattern caused by brushing. ${ }^{25,28}$ In comparison, nanohybrid and microhybrid composites, such as Filtek Z250 $\mathrm{XT}$ and Ultrafill, contain a higher range of particle sizes. Ultrafill, for instance, presents particles up to $2.2 \mu \mathrm{m}$, whereas Llis - a nanohybrid compositepresents particles of $0.8 \mu \mathrm{m}$ on average. This statement is supported by Figure 1, in which Filtek Z250 XT after brushing presents a higher range of filler sizes, with greater spherical particles than those of the other composites. Larger particles tend to protrude further through the worn surface and present a longer cantilever than the smaller ones, implying that they are ejected from the resin composite matrix early in face of challenges. ${ }^{25,37,38}$ Conversely, composites with small fillers normally present decreased interparticle spacing, thus protecting the organic matrix from the wear of brushing. ${ }^{25}$ Regarding spatial conformation, irregular-shaped filler particles tend to be more wearresistant than spherical ones. This occurs because the irregular filler particles might have a higher specific area for adhesion, even though both types of particles are treated with silane coupling. ${ }^{39,40}$ Thus, resin composites with larger spherical filler particles tend to lose their filler more easily, resulting in greater surface irregularities. Furthermore, if these filler particles are dislodged from the matrix during brushing, they could participate as an abrasive medium..$^{41}$ This explains the contrasting roughness values obtained by Filtek Z250 XT and/or Ultrafill and Llis after brushing.

It should further be mentioned that the rheological features of Ultrafill make it less malleable and more viscous, thereby causing the incorporation of voids, as may be noticed in Figure. Composite viscosity plays an important role in the quality of the restoration. ${ }^{42,43}$ The effect of monomer composition on viscosity has been explored extensively. For instance, adding TEGDMA of low molecular weight to an organic matrix should reduce composite viscosity and better enable its placement in the cavity ${ }^{44}$ Furthermore, the influence of filler particles, including characteristics of number, size and surface area, on composite rheological properties has been well reported. ${ }^{43}$ According to the Ultrafill manufacturer, the composite contains Bis-GMA and UDMA, both monomers of high molecular weight. The number and size of the filler particles are disclosed, but their spatial conformation remains unknown to the consumer. Since the specific material description is undetermined, the impact of each particular compound on the final material properties is difficult to predict. However, the high number of fillers associated with the absence of a monomer of low molecular weight in the Ultrafill composition may already indicate why this composite presents high viscosity, incorporation of voids and high surface roughness, both before and after simulated brushing. The low gloss values of Ultrafill, especially before brushing, should also be correlated to its characteristics.

In view of these points, it should be highlighted that Filtek Z250 XT showed higher gloss values than all the other composites before brushing, and higher 
gloss values than Llis, Fill Magic and Applic after brushing. This finding corroborates the studies that indicate an inverse correlation between roughness and gloss. ${ }^{23,31}$ Nevertheless, composite gloss may be further influenced by the difference in the refractive indexes of the organic matrix and particles. ${ }^{45}$ Filtek Z250 XT has high filler content by weight (82\%). This feature, added to its filler particularities-nano-zirconia/ silica spheroidal particles-may have influenced its gloss. Thus, although the composite presented high roughness, its spherical particles must have had an influence on its light reflection and gloss.

The highest microhardness values of Filtek Z250 XT over the other composites, both before and mainly after brushing, also corroborate our theory, considering that hard zirconia particles might have influenced the result. Similarly, Takahashi et al. ${ }^{23}$ reported the high mechanical resistance of Filtek Z250 XT. Nevertheless, the variability of microhardness among the composites before brushing is an issue that should be discussed, since the exposure of fillers is lower after brushing. Indeed, the characteristics of an organic matrix could have influenced the result. The mechanical behavior of a polymer matrix is directly associated with the creation of a three-dimensional network, ${ }^{46}$ as well as with network crystallinity. ${ }^{47}$ Thus, the chemical compounds and physical aspects of the polymer are important for the quality and type of this reaction..$^{48}$ The distinct formulations of each resin composite result in different qualities of polymers. An interesting finding to be observed is that the resin composite presenting the highest value of microhardness before brushing was also the most expensive one (Table 1). Although the monomer composition might be similar for all composites, data such as exact quantities of monomers, and type of photo-initiators, activators, inhibitors and fillers are incomplete. As already mentioned, since the specific material description is unknown, the impact of each particular compound on the final material properties is difficult to predict. One could infer that the differences in the light curing periods applied to each resin composite in this study could interfere with the microhardness results. Price et al. ${ }^{49}$ elucidated that differences between microhardness among brands of resin composites does not mean that one composite is better cured than the other. The differences between time of light exposure for each composite may be associated with the filler loading. ${ }^{50}$ In other words, the resin composites that presented the highest filler content herein had a curing time of $40 \mathrm{~s}$ (Table 1). Thus, an increase in the curing time for these composites would be needed for adequate polymerization, but should not necessarily influence the microhardness results.

The behavior of the composites regarding their color variation $\left(\Delta \mathrm{E}\right.$ and $\left.\Delta \mathrm{E}_{00}\right)$ must be addressed as well. Filtek Z250 XT presented higher color variation than Fill Magic. The other composites showed a statistical similarity to Filtek Z250 XT and Fill Magic. Despite the differences observed between both composites, the $\Delta \mathrm{E}$ and $\Delta \mathrm{E}_{00}$ values presented by both of them were less than 2.7 and 1.8, respectively, i.e. they did not represent any clinically visible color change..$^{20,21,51}$ Interestingly, an analysis of all the CIE L*, $\mathrm{a}^{*}, \mathrm{~b}^{*}$ system axes reveals that the $\Delta \mathrm{L}$ values (luminosity) and the $\Delta \mathrm{b}$ values (yellow/blue coordinate) are similar for all groups. No composite was necessarily lighter or darker, yellower or bluer than the others. The $\Delta \mathrm{a}$ coordinate (red/green) also revealed that there were no statistical differences between Filtek Z250 XT and Fill Magic. Ashok and Jayalakshmi explain that different factors are responsible for the color presented by resin composites, such as: organic matrix type, filler particle size, polymerization depth, and pigment agents..$^{52}$ Thus, although all the composites tested have an A2 shade, subtle changes among them may be observed due to differences in their compositions. As already discussed, the findings presented in this study also indicate that the mechanical action of brushing and abrasion provided by toothpaste removed part of the organic matrix from the composites, thus leading to even greater discrepancies in their compositions and possible color changes.

\section{Conclusion}

Although this research used simulated tooth brushing, it can be said that low-cost Brazilian resin composites presented properties similar or superior to the international one in regard to roughness and color, and properties similar or inferior to the 
international one in regard to microhardness and gloss. Accordingly, in a situation of scarce resources, low-cost Brazilian composites might be an acceptable cost-effective restorative alternative. Nevertheless, further studies are needed to determine whether the price of resin composites is directly proportional to their quality. For this purpose, more properties of lowcost Brazilian resin composites should be assessed, including their long-term behavior. Collaboration with health economists to guide future research would also be highly recommended in order to evaluate the comparative effectiveness and cost-effectiveness of these composites.

\section{Acknowledgments}

The authors would like to thank the Coordenação de Aperfeiçoamento de Pessoal de Nível SuperiorBrasil (Capes - Funding code 001) and the Brazilian National Council for Scientific and Technological Development (CNPq) for their support.

\section{References}

1. Chesterman J, Jowett A, Gallacher A, Nixon P. Bulk-fill resin-based composite restorative materials: a review. Br Dent J. 2017 Mar;222(5):337-44. https://doi.org/10.1038/sj.bdj.2017.214

2. Maas MS, Alania Y, Natale LC, Rodrigues MC, Watts DC, Braga RR. Trends in restorative composites research: what is in the future? Braz Oral Res. 2017 Aug;31(1 suppl 1):e55. https://doi.org/10.1590/1807-3107bor-2017.vol31.0055

3. Araujo MF, Correia CL, Groisman S, Toledo E. [Dental private insurance: vision of the dentists of the city of Duque de Caxias/RJ]. Rev Bras Odontol. 2012 jul/dez;69(2):165-9. Portuguese.

4. Garcia LP, Sant'anna AC, Magalhaes LC, Aurea AP. [Healthcare expenses of Brazilian families living in metropolitan areas: composition and trends during the period from 1995 to 2009]. Cienc Saude Coletiva. 2013;17(1):115-28. Portuguese. https://doi.org/10.1590/S1413-81232013000100013

5. Malta DC, Stopa SR, Pereira CA, Szwarcwald CL, Oliveira M, Reis AC. Private HEALTH CARE COVERAGE in the Brazilian population, according to the 2013 Brazilian National Health Survey. Cienc Saúde Coletiva. 2017 Jan;22(1):179-90. https://doi.org/10.1590/1413-81232017221.16782015

6. Hebling E, Gonçalves RL, Queluz DP. Cost analysis of materials used in Class III, IV and V composite resin restorations. Braz J Oral Sci. 2013;12(4):298-306. https://doi.org/10.1590/S1677-32252013000400005

7. Drummond F. Methods for the economic evaluation of health care programmes. New York: Oxford; 2005.

8. Brignardello-Petersen R, Carrasco-Labra A, Glick M, Guyatt GH, Azarpazhooh A. A practical approach to evidence-based dentistry: understanding and applying the principles of EBD. J Am Dent Assoc. 2014 Nov;145(11):1105-7. https://doi.org/10.14219/jada.2014.102

9. Carrasco-Labra A, Brignardello-Petersen R, Glick M, Azarpazhooh A, Guyatt G. How to use evidence-based dental practices to improve clinical decision-making. Chicago: American Dental Association; 2019.

10. Schwendicke F, Göstemeyer G, Stolpe M, Krois J. Amalgam Alternatives: Cost-Effectiveness and Value of Information Analysis. J Dent Res. 2018 Nov;97(12):1317-23. https://doi.org/10.1177/0022034518782671

11. Kelly PG, Smales RJ. Long-term cost-effectiveness of single indirect restorations in selected dental practices. Br Dent J. 2004 May;196(10):639-43. https://doi.org/10.1038/sj.bdj.4811283

12. Ferracane JL. Resin composite: state of the art. Dent Mater. 2011 Jan;27(1):29-38. https://doi.org/10.1016/i.dental.2010.10.020

13. International Organization for Standardization - ISO. ISO/TS:14569-2. Dental materials. Guidance on testing of wear - Part 2: Wear by two- and/or three body contact. Geneva: International Organization for Standardization; 2001.

14. International Organization for Standardization - ISO. ISO:11609. Dentistry — Dentifrices — Requirements, test methods and marking. Geneva: International Organization for Standardization; 2010.

15. Wang L, Garcia FC, Amarante de Araúio P, Franco EB, Mondelli RF. Wear resistance of packable resin composites after simulated toothbrushing test. J Esthet Restor Dent. 2004;16(5):303-14. https://doi.org/10.1111/i.1708-8240.2004.tb00058.x

16. Monteiro B, Spohr AM. Surface roughness of composite resins after simulated toothbrushing with different dentifrices. J Int Oral Health. 2015 Jul;7(7):1-5.

17. Suzuki T, Kyoizumi H, Finger WJ, Kanehira M, Endo T, Utterodt A, et al. Resistance of nanofill and nanohybrid resin composites to toothbrush abrasion with calcium carbonate slurry. Dent Mater J. 2009 Nov;28(6):708-16. https://doi.org/10.4012/dmj.28.708

18. Catelan A, Araújo LS, Silveira BC, Kawano Y, Ambrosano GM, Marchi GM, et al. Impact of the distance of light curing on the degree of conversion and microhardness of a composite resin. Acta Odontol Scand. 2015 May;73(4):298-301. https://doi.org/10.3109/00016357.2014.946965 
Ferretti MA, Pereira R, Lins RBE, Soares MGC, Pinto LJH, Martins LRM et al.

19. Theobaldo JD, Vieira-Junior WF, Cortellazzi KL, Marchi GM, Lima DA, Aguiar FH. Effects of cigarette smoke on color, roughness and gloss of high-viscosity bulk-fill resin composites. Am J Dent. 2020 Apr;33(2):83-8.

20. Paravina RD, Ghinea R, Herrera LJ, Bona AD, Igiel C, Linninger M, et al. Color difference thresholds in dentistry. J Esthet Restor Dent. 2015 Mar-Apr;27 Suppl 1:S1-9. https://doi.org/10.1111/jerd.12149

21. Pérez MM, Ghinea R, Rivas MJ, Yebra A, lonescu AM, Paravina RD, et al. Development of a customized whiteness index for dentistry based on CIELAB color space. Dent Mater. 2016 Mar;32(3):461-7. https://doi.org/10.1016/j.dental.2015.12.008

22. International Organization for Standardization - ISO. ISO:2813. Paints and varnishes - Determination of gloss value at 20 degrees, 60 degrees and 85 degrees. Geneve: International Organization for Standardization; 2014.

23. Takahashi R, Jin J, Nikaido T, Tagami J, Hickel R, Kunzelmann KH. Surface characterization of current composites after toothbrush abrasion. Dent Mater J. 2013;32(1):75-82. https://doi.org/10.4012/dmi.2012-160

24. Mozzaquatro LR, Rodrigues CS, Kaizer MR, Lago M, Mallmann A, Jacques LB. The Effect of Brushing and Aging on the Staining and Smoothness of Resin Composites. J Esthet Restor Dent. 2017 Apr;29(2):E44-55. https://doi.org/10.1111/jerd.12293

25. Ruivo MA, Pacheco RR, Sebold M, Giannini M. Surface roughness and filler particles characterization of resin-based composites. Microsc Res Tech. 2019 Oct;82(10):1756-67. https://doi.org/10.1002/jemt.23342

26. Bollen CM, Lambrechts $P$, Quirynen M. Comparison of surface roughness of oral hard materials to the threshold surface roughness for bacterial plaque retention: a review of the literature. Dent Mater. 1997 Jul;13(4):258-69. https://doi.org/10.1016/S0109-5641(97)80038-3

27. Khuraif AAAA. An in vitro evaluation of wear and surface roughness of particulate filler composite resin after tooth brushing. Acta Odontol Scand. 2014;72(8):977-83. https://doi.org/10.3109/00016357.2014; 933251

28. Oliveira GU, Mondelli RF, Charantola Rodrigues M, Franco EB, Ishikiriama SK, Wang L. Impact of filler size and distribution on roughness and wear of composite resin after simulated toothbrushing. J Appl Oral Sci. 2012 Sep-Oct;20(5):510-6. https://doi.org/10.1590/S1678-77572012000500003

29. Rana M, Upadhya M, Jaiswal A, Tyagi K. Evaluation of surface roughness of nanofilled composite restorations after simulated tooth brushing using various dentifrices. Kathmandu Univ Med J (KUMJ). 2018 Jul-Sep;16(63):231-6.

30. Puckett AD, Fitchie JG, Kirk PC, Gamblin J. Direct composite restorative materials. Dent Clin North Am. 2007 Jul;51(3):659-75. https://doi.org/10.1016/i.cden.2007.04.003

31. Voltarelli FR, Santos-Daroz CB, Alves MC, Cavalcanti AN, Marchi GM. Effect of chemical degradation followed by toothbrushing on the surface roughness of restorative composites. J Appl Oral Sci. 2010 Dec;18(6):585-90. https://doi.org/10.1590/S1678-77572010000600009

32. Kon M, Kakuta K, Ogura H. Effects of occlusal and brushing forces on wear of composite resins. Dent Mater J. 2006 Mar;25(1):183-94. https://doi.org/10.4012/dmj.25.183

33. Lefever D, Perakis N, Roig M, Krejci I, Ardu S. The effect of toothbrushing on surface gloss of resin composites. Am J Dent. 2012 Feb;25(1):54-8.

34. Heintze SD, Forjanic M, Rousson V. Surface roughness and gloss of dental materials as a function of force and polishing time in vitro. Dent Mater. 2006 Feb;22(2):146-65. https://doi.org/10.1016/i.dental.2005.04.013

35. Heintze SD, Forjanic M, Ohmiti K, Rousson V. Surface deterioration of dental materials after simulated toothbrushing in relation to brushing time and load. Dent Mater. 2010 Apr;26(4):306-19. https://doi.org/10.1016/j.dental.2009.11.152

36. da Costa J, Adams-Belusko A, Riley K, Ferracane JL. The effect of various dentifrices on surface roughness and gloss of resin composites. J Dent. 2010;38(2 Suppl 2):e123-8. https://doi.org/10.1016/i.jdent.2010.02.005

37. Söderholm KJ, Richards ND. Wear resistance of composites: a solved problem? 1998 May-June;46(3):256-63.

38. Kooi TJ, Tan QZ, Yap AU, Guo W, Tay KJ, Soh MS. Effects of food-simulating liquids on surface properties of giomer restoratives. Oper Dent. 2012 Nov-Dec;37(6):665-71. https://doi.org/10.2341/11-419-L

39. Miyasaka T, Yoshida T. Effect of binary and ternary filler mixtures on the mechanical properties of composite resins. Dent Mater J. 2000 Sep;19(3):229-44. https://doi.org/10.4012/dmj.19.229

40. Turssi CP, Ferracane JL, Vogel K. Filler features and their effects on wear and degree of conversion of particulate dental resin composites. Biomaterials. 2005 Aug;26(24):4932-7. https://doi.org/10.1016/i.biomaterials.2005.01.026

41. Shinkai K, Taira Y, Suzuki S, Kawashima S, Suzuki M. Effect of filler size and filler loading on wear of experimental flowable resin composites. J Appl Oral Sci. 2018 Feb;26(0):e20160652. https://doi.org/10.1590/1678-7757-2016-0652

42. Lee IB, Son HH, Um CM. Rheologic properties of flowable, conventional hybrid, and condensable composite resins. Dent Mater. 2003 Jun;19(4):298-307. https://doi.org/10.1016/S0109-5641(02)00058-1

43. Habib E, Wang R, Zhu XX. Correlation of resin viscosity and monomer conversion to filler particle size in dental composites. Dent Mater. 2018 Oct;34(10):1501-8. https://doi.org/10.1016/i.dental.2018.06.008

44. Beun S, Bailly C, Devaux J, Leloup G. Rheological properties of flowable resin composites and pit and fissure sealants. Dent Mater. 2008 Apr;24(4):548-55. https://doi.org/10.1016/i.dental.2007.05.019 
- Characterization of low-cost Brazilian resin composites submitted to tooth brushing

45. Lemos CA, Mauro SJ, Santos PH, Briso AL, Fagundes TC. Influence of mechanical and chemical degradation in the surface roughness, gloss, and color of microhybrid composites. J Contemp Dent Pract. 2017 Apr;18(4):283-8. https://doi.org/10.5005/ip-journals-10024-2032

46. Izumi M, Ohnuki H. Comparative study on Langmuir-Blodgett films and crystals based on TTF derivatives with long alkyl chains. Mat Meas Mol Eletron. 1996;81:123-36. https://doi.org/10.1007/978-4-431-68470-1_10

47. Hutchings LR. Macromolecular engineering: a synthetic perspective. Plast Rubber Compos. 2006;35(10):403-9. https://doi.org/10.1179/174328906X149754

48. Durner J, Obermaier J, Draenert M, llie N. Correlation of the degree of conversion with the amount of elutable substances in nano-hybrid dental composites. Dent Mater. 2012 Nov;28(11):1146-53. https://doi.org/10.1016/i.dental.2012.08.006

49. Price RB, Fahey J, Felix CM. Knoop microhardness mapping used to compare the efficacy of LED, QTH and PAC curing lights. Oper Dent. 2010 Jan-Feb;35(1):58-68. https://doi.org/10.2341/09-055-L

50. Halvorson RH, Erickson RL, Davidson CL. The effect of filler and silane content on conversion of resin-based composite. Dent Mater. 2003 Jun;19(4):327-33. https://doi.org/10.1016/S0109-5641(02)00062-3 PMID:12686298

51. Reinhardt JW, Balbierz MM, Schultz CM, Simetich B, Beatty MW. Effect of Tooth-Whitening Procedures on Stained Composite Resins. Oper Dent. 2019 Jan/Feb;44(1):65-75. https://doi.org/10.2341/17-301-L

52. Ashok NG, Jayalakshmi S. Factors that influence the color stability of composite restorations. Int J Orofac Biol. 2017;1(1):1-3. https://doi.org/10.4103/ijofb.ijofb_5_16 